\title{
Online customer engagement: a practical exploration of antecedents and metrics for new content marketers
}

\author{
Cynthia D. Wiggins ${ }^{1,2}$
}

Received: 19 June 2021 / Accepted: 15 December 2021 / Published online: 19 January 2022

(C) The Author(s) 2022

\begin{abstract}
The ability of new content marketing companies and marketing practitioners to engage customers online depends on their understanding of the impact of antecedents on critical online customer engagement metrics. However, there has been little scholarly research exploring online customer engagement in the context of complex, real-world environments that could guide the strategies of new brands and start-up companies seeking to establish an online presence. This paper identifies the antecedents and metrics required for identifying an appropriate online customer engagement (OCE) strategy in the context of a start-up content marketing company called ABC Investments (a pseudonym) and of more established social media platforms, such as Facebook and Instagram. Eleven OCE antecedents and six metrics were originally proposed but on completion of the research, twelve antecedents- including one new one (human face)- were determined to have impacted OCE metrics. Finally, this paper shows how antecedent and metric research can be used to develop OCE strategies.
\end{abstract}

Keywords Online customer engagement · Content marketing · Start-up · Facebook · Instagram $\cdot$ Antecedents $\cdot$ Metrics $\cdot$ Consequences

\section{Introduction}

Smart Insights (2021) and Perrin (2015) indicated that there is ongoing growth in internet and social media usage globally. As of January 2021, there were 4.20 billion active social media users, representing approximately $53.6 \%$ of the global

\footnotetext{
Cynthia D. Wiggins

cynthia.d.wiggins@gmail.com

1 University of Liverpool, Liverpool, UK

2 ABC Investments, Saint Michael, Barbados
}

The results in this article were previously part of the author's thesis submission for their Doctor of Business Administration (DBA) at the University of Liverpool. 
population of more than 7.8 billion people, and an increase of $13.2 \%$ active social media users since January 2020 (Smart Insights 2021). Harmeling et al. (2017) posited that in the past decade there has been an explosion of interest in customer engagement among both marketing academics and practitioners, with the number of Google search hits for the term "customer engagement" increasing from zero in 2007 (Harmeling et al 2017), to more than 690 million as of April 7, 2021. Additionally, Chua and Banerjee (2013) and Abdul-Ghani et al. (2011) hypothesized that although customer engagement is not a new concept in marketing, the advent of the internet and social media have caused organisations, including those with a traditional brick-and-mortar presence, to seek to reshape how they engage customers online. Constantinides et al. (2008) suggested that the increase in online activity by consumers has made the internet the new frontier for customer engagement. Ashley and Tuten (2015) postulated that little is known about online customer engagement (OCE) antecedents and consequences, especially for new marketing initiatives or start-up companies, even though the importance of the internet and social media is widely recognised by scholars and practitioners of marketing. Most of the research on customer engagement or content marketing, however, have focus on companies which already have established brands or on one social media platform- usually Facebook. Additionally, previous studies have not taken into consideration that any new content marketing company will need to start from ground zero, with little or no followers or online fans. Thereby requiring the need of content marketers to understand how to engage their customer and development an engagement strategy specific to their customers. Moreover, the dominance of key players such as Facebook and Instagram in the content marketing environment means that new content marketers or marketing companies, such as ABC Investments, must either use, or compete with more than one social media giant, thereby making the environment to which start-up social media marketing companies have to traverse, even more complex. This study seeks to reduce these online customer engagement and content marketing research gaps and is among the first to investigate the impact that changes in content and platform have on customer engagement in a live environment, and in the context of a start-up content marketing company.

This research will provide a real-world investigation of the drivers and metrics of OCE by using a start-up content marketing platform, ABC Investments (a pseudonym), along with Facebook and Instagram, two of the most popular social media platforms (Pilon 2017). For this research, a conceptual model and variables were developed based on literature focused on both online and offline customer engagement. The research considered both content-based antecedents (e.g., vividness, content type and frequency of post) and platform-based antecedents (e.g., search engine optimisation and tailored experience). Eleven antecedents and six metrics were initially identified but, by the end of the research, twelve antecedents were found to impact significantly on these six metrics.

The remainder of this paper consists of a review of the relevant literature, followed by discussions of the research question and methodology, the presentation and discussion of the findings; and finally a summary and a brief discussion of the limitations of the present research and potentially fruitful future research in this area. 


\section{Literature review}

\section{Online engagement: antecedents and consequences}

Research by Fortin and Dholakia (2005), Srinivasan et al. (2002) and De Vries et al. (2012) focused on content and platform-derived antecedents that affect OCE. These three studies proposed the following as antecedents of OCE: interactivity, interactive continuum (different levels or methods of interaction), vividness, social presence (two-way communication), involvement (where the customer takes part in the content through quizzes and polls and are viewed as part of the content), community (social spaces) and choice (different content options). Rauschnabel et al. (2012), on the other hand, postulated that engagement was primarily driven by content design and posting features such as day of the week, message length, product category, post size, media elements and response invitations. They also suggested that antecedents such as large posting or advertisement size and the number of media elements increased engagement, while lengthy text had a negative impact on engagement. Van Doorn et al. (2010), in contrast, highlighted the role of context-based antecedents, such as "competitive factor", political, economic, social, and technological factors.

In relation to the consequences of OCE, Sun et al. (2006), and Pansari and Kumar (2017) postulated that when customers are engaged companies can expect the following outcomes: referrals of the content, company, brand or platform to other customers (customer referrals); impact on behaviour of another individual (customer influence); and customers sharing their knowledge of the content, product or brand suggesting possible improvements (customer knowledge). In contrast, Sun et al. (2006) and Pansari and Kumar (2017), along with Van Doorn et al. (2010), did not only classified the consequences of customer engagement in relation to the customer (i.e., the cognitive, attitudinal, emotional, physical, welfare, temporal and identity) but also in relation to the firm (i.e., financial, reputational, regulatory and competitive, employees and products consequences). Van Doorn et al. (2010) also identified a miscellaneous category that included macro-OCE consequences such as economic surplus, social surplus, regulation, and cross-brand and cross- customer. Although, the often-cited studies by Sun et al (2006), Pansari and Kumar (2017), and Van Doorn et al. (2010) facilitated a better understanding of OCE by identifying and classifying potential consequences the findings in these research papers were too abstract to be of more than limited use in relation to the complexities and requirements of real-world customer engagement. Developing an effective, practical content marketing strategy requires identifying concrete, valuebased metrics for determining when marketing objectives have been met, the extent to which these objectives are met, and more importantly when a strategy needs to be adjusted and improved (Berman 2012 and Cheong et al. 2010). It was thus also necessary to explore the literature on online engagement and marketing metrics.

\section{Online engagement and content marketing metrics}

A metric is defined here as a measuring system that describes or quantifies a characteristic, trend, evolution, dynamic or process (Peters et al. 2013). Peters et al. (2013) 
also noted that in business, as well as in research, metrics are employed to define the objectives and goals of an undertaking and to measure the degree to which these objectives have been met, completed, or deviated. Farris et al. (2006) identified different types of metrics, such as amounts (e.g., visits, users or sales), percentages (e.g., percentage of males versus females), counts (e.g., the number of competitors), indices, and ratings. Ailawadi et al. (2003) similarly contended that metrics should be theoretically grounded, encompass all facets that need to be measured, be able to flag any downturns or improvements, and provide diagnostic insights. Farris et al. (2006) further contended that metrics should be able to capture the future potential of the variable being measured as well as being credible, intuitive, easily, and universally understood, stable over time, reliable, and robust.

Moro et al. (2016) in contrast, distinguished two main types of metrics in relation to engagement with online posts. The first metric is visualisation, which measures the number of "impressions" or number of times a post was loaded on a user's page or browser, whether organically, through another user or via an advertisement. The second type of metric is interactions and measures the "engagement" of a user with a post or content including clicks, likes, reactions, shares, comments, comment replies, video or image views and tagging. Moro et al. (2016) considered interactions a stronger measure of customer engagement than visualisation since it measures the user's explicit action with post and, therefore, constitute their interests in the content.

On the other hand, Baltes (2015) and Bonsón and Ratkai (2013) suggested the need to monitor more advanced, business-specific metrics, that were more relevant to practice such as website visits, page views, bounce rate, and time spent on the website. Although neither of these studies provided equations or the mathematical expressions for the metrics, their proposed list of metrics did provide sufficient direction in the types of social media metrics required to measure OCE and were, therefore, incorporated into this study.

\section{Research question development}

\section{Conceptual model}

Mehrabian and Russell's (1974) Stimulus-Organism-Response (SOR) theory provided the foundation for the conceptual model used in this study. The SOR theory has been used to underpin conceptual models for research into OCE by authors such as Peng and Kim (2014), Islam and Rahman (2017), and Kim and Lennon (2013). The premise of this theory is that an environmental stimuli (S) affects an organism $(\mathrm{O})$, such as a customer, and elicits a response (R), which in the context of OCE, would take the form of engagement or non-engagement (also known as avoidance) with the content. In this study, the stimuli were changes to the content and the platform, the organisms were the users or customers, and the responses were engagement actions, as measured by the quantitative OCE metrics (see Fig. 1).

The SOR framework and the literature discussed above were used to identify several content and platform antecedents, and metrics for OCE. An initial conceptual 
research question model and online customer engagement were developed based on the comparable research by Van Doorn et al. (2010), Thakur (2016), Tafesse (2015), Mpinganjira (2016), Moro et al. (2016) and Kujur and Singh (2017), see Fig. 2. The metrics were drawn from the work of Cvijikj and Michahelles (2013), Baltes (2015), and Bonsón and Ratkai (2013) and further refined or expanded upon. The initial assumption was that each antecedent impacted equally on each outcome and that the results of the iterative research analysis process would provide a deeper understanding of the impact that the content or platform antecedents have on the relevant metric.

\section{Content antecedents}

\section{Time and day of the week}

As discussed by Rauschnabel et al. (2012), Cvijikj and Michahelles (2013), and De Vries et al. (2012), time and day of the week are significant indicators of how much users are likely to engage with content. For example, customers are likely to engage more with posts made during the evening or on Fridays (Landsverk 2014). In light of this, the following research questions were proposed:

Q1a: Does the time of day impact positively on OCE?

Q1b: Does the day of the week impact positively on OCE?

\section{Content type}

This refers to whether the content of a particular post is primarily an image or images, text, a video or videos, a listicle, a contest, a quiz, or a game. It is thought that users will engage more with some types of content than others (Elsayed 2017).

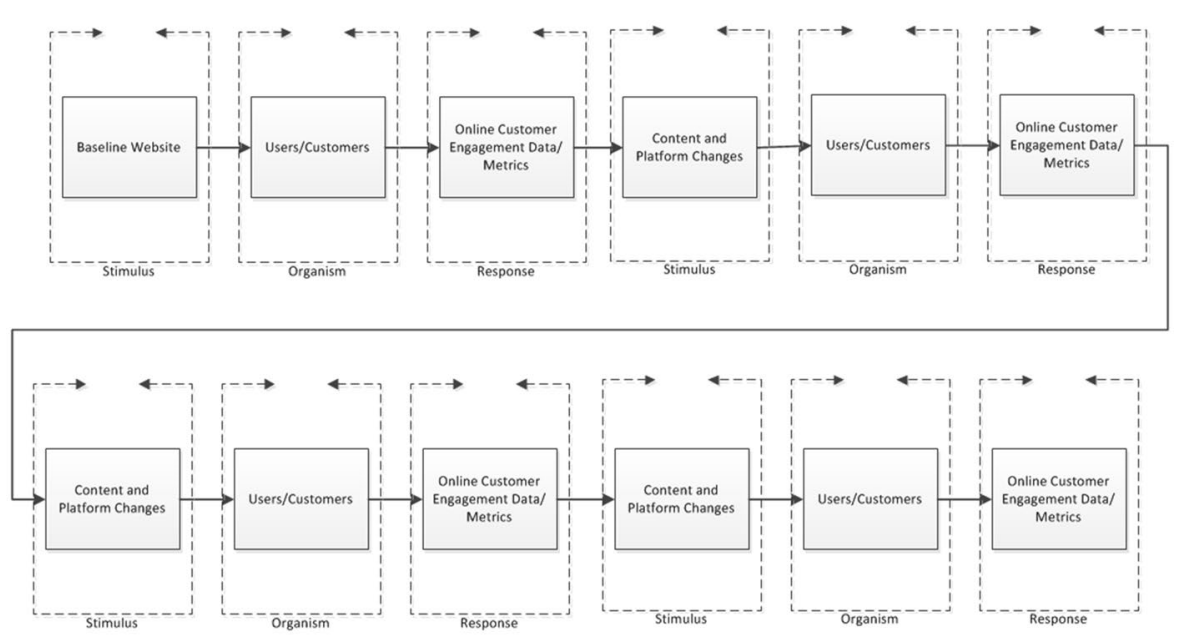

Fig. 1 Research Conceptualisation Using the S-O-R Framework 


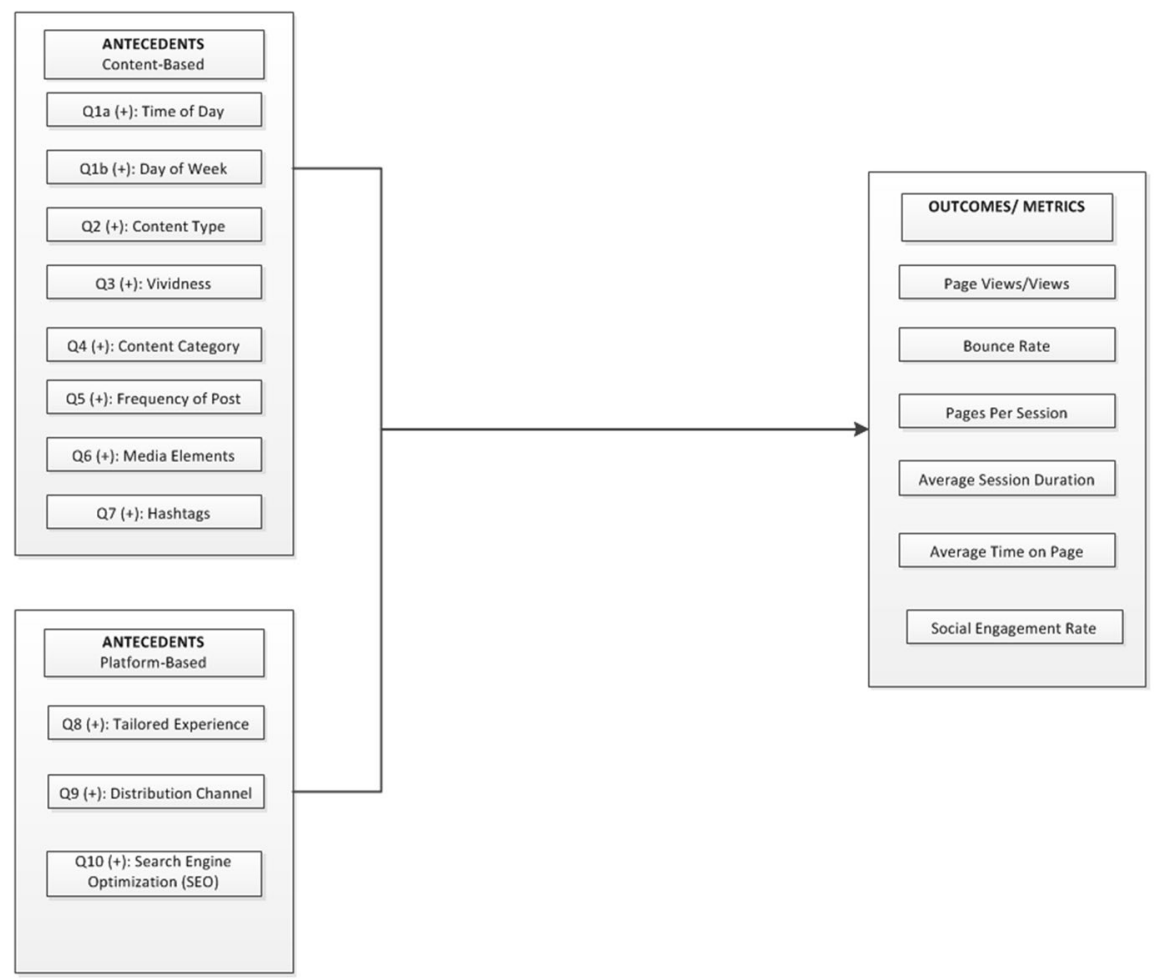

Fig. 2 Conceptual model of research questions and online customer engagement

For example, greater engagement may be elicited from content that gives users the opportunity to win a prize- even a small one- than content that is simply to be passively viewed. The following research question was, therefore, proposed:

Q2: Does the different content types impact positively on OCE?

\section{Vividness}

This refers to whether the content conveys its message using real people, incorporates high-quality sound and images, and uses colour photos or videos. Tafesse (2015), Fortin and Dholakia (2005), and De Vries et al. (2012) have found that the extent of vividness determines the number and type of the user's senses that are stimulated and this influences how many views or likes the content receives. For example, content that only includes text may not be viewed as much as content that has photos or videos. The research question proposed is as follows:

Q3: Does the vividness of content have a positive impact on OCE? 


\section{Content category}

This OCE antecedent was proposed by several authors, including De Vries et al. (2012), Tafesse (2015), and Gavilanes et al. (2018). It refers to the focus of the content for example, whether the content is focused on informing the user, entertaining the user or providing the user with sales information. The following research question was proposed:

Q4: Does the content category impact positively on OCE?

\section{Frequency of posting}

Srinivasan et al. (2002) showed that frequency of posting has an impact on customer engagement. When people are presented with content frequently, they are more likely to exhibit engagement behaviours than if the content were only presented infrequently. For example, the co-founder of Reddit, Steve Huffman, said that he and his business partner Alexis Ohanian set up several hundred accounts in the company's initial start-up phase. This ensured that there was no blank space on the site. They made posts every day to encourage people to visit their platform. This organic traffic increased their ranking on Google (Huffman 2012). The following research question was proposed in relation to this antecedent:

Q5: Does the frequency of the post-impact positively on OCE?

\section{Media elements}

This metric refers to the number of photos, videos or graphics included in a post or other piece of content. Rauschnabel et al. (2012) show that factors such as word count and the number of media elements in a post affect how much customers will engage with the content. The following research question was proposed in relation to this antecedent.

Q6: Does the number of media elements positively impact the level of OCE?

\section{Hashtags}

This metric refers to the tags (made using the "\#" symbol) that precede a word or words on social media platforms and mark the main subjects, ideas, events, locations, or emotions featured in posts (Highfield and Leaver 2015). Additionally, the use of hashtags on social media platforms indicates the interests of the user (Koch and Benlian 2015). The idea is that, if a user has previously demonstrated interest in a specific topic, they are likely to remain interested in the future and are, therefore, more likely to engage with relevant content than users who have not engage with similar content before. Content that targets established user interests is, therefore, likely to achieve greater engagement. The following research question was, therefore, derived:

Q7: Do hashtags have a positive impact on OCE? 


\section{Platform antecedents}

\section{User-tailored experience}

This metric denotes the fact that websites and platforms that feature content tailored to the specific interest of users are more likely to achieve higher levels of engagement (Constantinides 2002; Pophal 2015; Srinivasan et al. 2002).

Q8: Does tailoring a platform to user interests have a positive impact on OCE?

\section{Distribution channel}

This metric refers to the location where the content will be made available to users, including the $\mathrm{ABC}$ Investments platform and other more well established social media platforms (Constantinides 2006; Kee and Yazdanifard 2015; Mahajan and Venkatesh 2000; Kalyanam and McIntyre 2002; Tse and Soufani 2003). As with distribution channels in the traditional marketing mix, the location where content is distributed is a key factor in relation to the likely level of user engagement. Different distribution channels have different features and algorithms and so can either help or hinder content from being seen and engaged with. The following research question was derived in relation to this metric:

Q9: Does the distribution channel used have a positive impact on the social engagement rate?

\section{Search engine optimisation (SEO)}

This metric refers to the process by which the visibility of a website or platform is enhanced in an effort to ensure that it is ranked highly-preferably on the first page of relevant internet searches e.g. Google. The internet is so vast- with search engines often returning millions of results per search- that any new company, website, or content marketing platform faces the significant initial challenge of getting noticed (Evans 2007). If the relevant content or platform are properly optimised, they will be more visible, thereby driving engagement. The following research question was proposed in relation to this antecedent:

Q10: Does the implementation of SEO impact positively on OCE?

\section{Metric details}

Farris et al. (2006) have pointed out that there are different types of metrics. Cvijikj and Michahelles (2013) identified several relevant outcomes, namely likes, comments and shares. Baltes (2015) and Bonsón and Ratkai (2013), by contrast, identified more realistic and practical metrics than described above. The following metrics to be used in this study are a consequence of combining these research proposals and ensuring that the chosen metrics have a real-world focus. 


\section{Page views}

The number of times a page, content or video is viewed by a user or the number of times an item of content is clicked.

\section{Bounce rate}

The percentage of visitors that navigate away from content after only interacting with one single content type or page. Unlike with the other metrics used, a lower the bounce rate equates with superior performance.

\section{Average pages per session}

This is the average number of webpages viewed by each user during each session. Repeated views of a single page are not counted.

\section{Average session duration}

The average length of a session, usually measured in hours, minutes and seconds.

\section{Average time on page}

The average amount of time users spend viewing a specific page or a set of pages.

\section{Social engagement rate}

This metric adds up engagement metrics specific to social media such as reactions, likes, comments, shares, votes, saves and other forms of engagement, and divides this total by the number of views (Cvijikj and Michahelles 2013). It is an important metric because it incapsulates the various forms of engagement on individual posts that are not covered by any of the other metrics. The following equation is used to determine this metric:

Social Engagement Rate $=\frac{\text { Reactions }+ \text { Comments }+ \text { Shares }+ \text { Votes }+ \text { Saves }+ \text { Other }}{\text { Views }} \times 100$ 


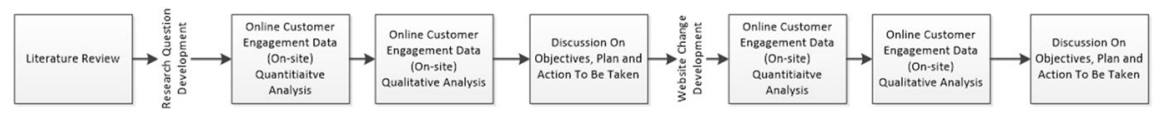

Fig. 3 MMAR research approach overview

\section{Research methodology and design}

\section{Research methodology}

A mixed-methods action research (MMAR) framework, as proposed by Ivankova and Wingo (2018), was used in this study. MMAR combines both action research and a mixed method of inquiry and facilitates robust results (Ivankova and Wingo 2018). The research utilized a mixed-method "handmaids" approach (Ivankova and Wingo 2018) to increase the validity and reliability of the results. The research consisted of four MMAR cycles involving a quantitative data collection cycle, a qualitative research cycle, as well as the testing of the recommended changes. This triangulation method sought to increase the validity of the results at both the data collection and analysis stages. Additionally, several data collection and analysis techniques were employed to increase the reliability of the results. Firstly, to reduce researcher error and bias, the quantitative data consisted of metrics widely used within the business and social media industries to measure customer online engagement with only erroneous data being removed from the data sets. In addition, as part of the qualitative cycle the interviewee was provided with the copy of the face-toface interview questions and answers to confirm their responses and subsequently sign-off on the results. Secondly, to reduce participant error and bias, at the qualitative cycles the interviewee was provided with the quantitative results and questions but was not allowed to collect the quantitative data. Additionally, interviews lasted for between $45 \mathrm{~min}$ to an hour to reduce participant fatigue; and at the beginning of every interview the participant was reminded that their answers would not affect their employment with the organization. Figure 3 illustrates the MMAR approach, which shows the overall process beginning from the initial development of the problem statement and highlights the influence of the literature on the development of the research questions. It also illustrates the connection between the quantitative and the qualitative cycles. Additionally, the subsequent sections provide details of the data collection - both quantitative and qualitative sources and analysis methods.

\section{Quantitative data collection: sources and analysis}

The quantitative data were collected from August 5, 2018 to March 31, 2019. They were generated from live OCE data collected from ABC Investments' own platform and from its Facebook business page and Instagram business profile using a criterion sampling method (Sandelowski 2000). As users engaged with the platform or content, the following metrics were collected either via Google Analytics (for ABC 


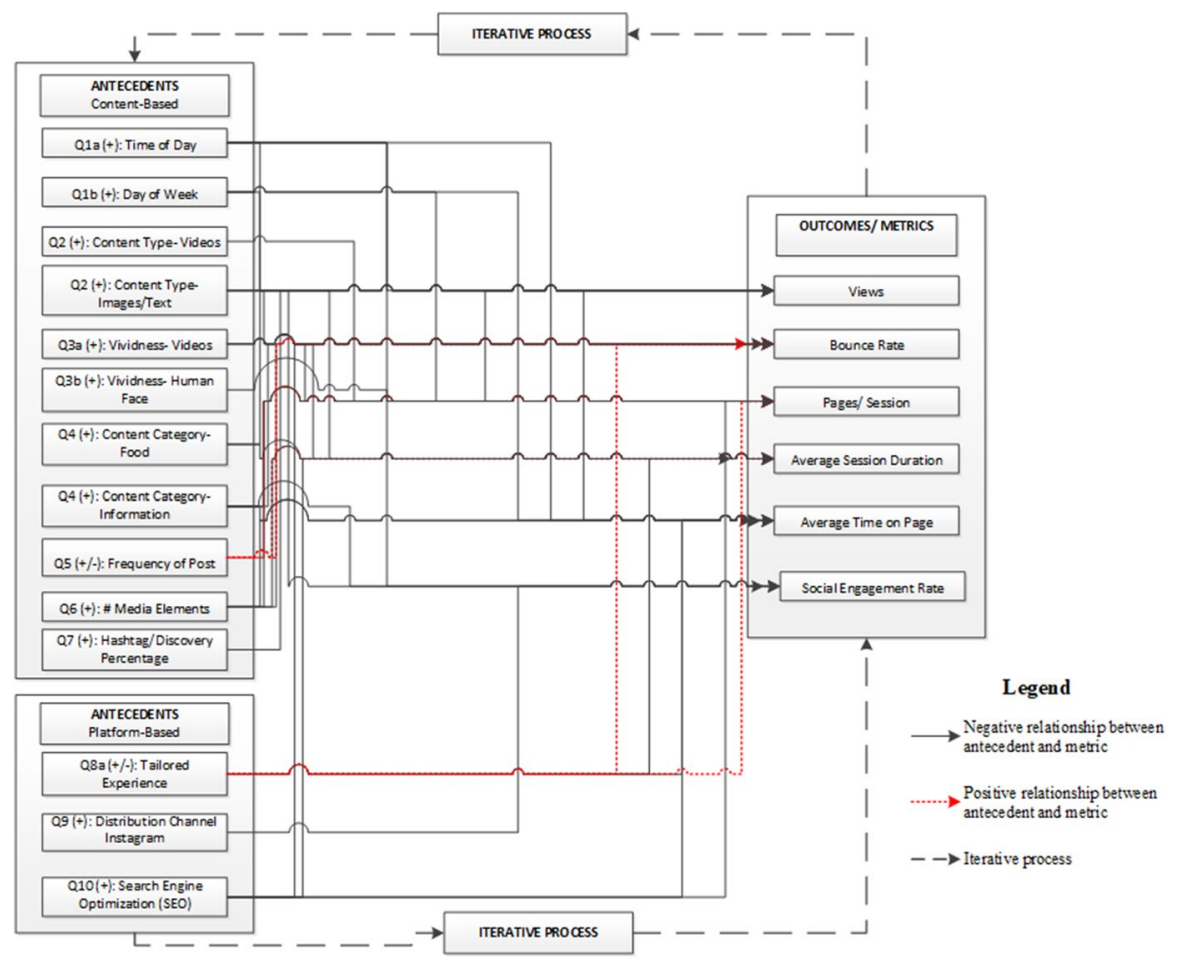

Fig. 4 Revised conceptual model of research questions and online customer engagement

Investments), Facebook, or Instagram: page views, bounce rate, pages per session, average session duration, average time on page and social engagement rate. The data were collated in a summarised format, with erroneous data removed for final analysis (e.g., error or 404 pages and views of policy or registration pages). The data were generated from 73 posts on the ABC Investments' platform, 37 posts on its Facebook business page and 29 on its Instagram business profile which accounted for a total of 99, 870 page views. Analysis was subsequently performed with Microsoft Excel, using a combination of equations, pivot tables, regression analyses. Graphs were generated to display the results and used as the inputs to the qualitative interview cycles.

\section{Qualitative data collection: sources and analysis}

The qualitative data were collected via semi-structured, in-depth, face-to-face interviews that provided rich data. A series of questions, along with the quantitative data and graphs, were provided to an interviewee (ABC's Investment's employee) as the inputs for the qualitative survey cycle. The sequential or handmaid approach was used to explain or clarify the results from the quantitative cycle (Ivankova and 
Wingo 2018; Creswell 2003; Easterby-Smith et al. 2012). Four interviews were conducted between September 3, 2018 and April 6, 2019. The interviewee was provided with the quantitative data and charts to review before the interview session. The thematic analysis technique was used during the qualitative cycle because the research questions or the themes structure of the research were already determined. Each iteration or cycle provided the input of the subsequent cycle until all the research questions or themes were addressed.

\section{Findings and discussion}

As previously mentioned, this study consisted of four distinct MMAR cycles which began on August 5, 2018 and ended on April 6, 2019, with each cycle lasting 3-4 weeks. At the beginning of the MMAR process, 11 research questions or antecedents were identified. As a result of the research process, there were antecedents that were either removed or redefined. In particular, the antecedent "hashtags" was redefined to the more practical "discovery percentage" and an additional antecedent, "human face" was added to make a final total of 12 antecedents. The research findings also revealed a more complex relationship between OCE antecedents and metrics than was not posited in previous OCE and content marketing research and in the original model (see Fig. 4 for the revised model). A summary of the findings and the resulting short-term and long-term OCE strategy are provided in the following paragraphs. The short-term strategies focused on those strategies that could be implemented within one to three months and that consist of the content or platform changes. While the long-term strategies focused on those strategies that may take more than 6 months to implement and may involve a paradigm shift for the organization, re-branding and/ or additional resources.

\section{Short-term strategies}

\section{Time of the day and day of week}

Cvijikj and Michahelles (2013) suggested that engagement would be higher during the week than on weekends and that there would also be more engaged in the evenings. However, the present study found peak customer engagement in page views, pages per session, bounce rate and average session duration on every day of the week with the exception of Fridays were it is customary for users to not be at home. Additionally, page views, pages per session, bounce rate and average session duration showed increased engagement on Saturdays when compared to Sundays. This study also found the greatest engagement for page views, pages per session, bounce rate and average time on page between 3 and 6 am before users went to work, between 12 and $1 \mathrm{pm}$ when users would more than likely be at lunch, and between 5 and $10 \mathrm{pm}$ when users would be home from work. The findings for the antecedent time of the day and day of the weeks suggests that customer engagement increases when people have free time, rather than on specific days or the week, or times of day. 
Resulting short-term strategy: These results suggest that posts should be made before 4 a.m. or before 4 p.m. to take advantage of the morning or evening peaks in user engagement and when users would be at their freest. As part of the strategy and for cost reasons, posts do not have to be made on non-peak user days but would have to be made early on the peak day to ensure that the non-peak user day benefits from the potential engagement from the peak engagement day. For example, posts should be made early Saturdays (peak user day) but would not have to be made on Sunday (non-peak user day). This strategy ensures that posts are sufficiently frequent and allows the marketer to take advantage of usage peaks while also managing the cost of content development.

\section{Content type}

Elsayed (2017) suggested that content type influences the level of engagement. This study found that content type did indeed have a positive influence on OCE but only on specific engagement metrics. Videos generated greater engagement than image/ text posts with respect to page views ( $459 \%$ greater), average time on page $(21 \%$ greater) and pages per session (247\% greater). Conversely, image/text posts performed better than video with respect to bounce rate (39\% decrease), session duration (68\% greater) and social engagement rate (44\% greater).

Resulting short-term strategy: these results suggest that video and image/text posts should be prioritised to maximise engagement.

\section{Vividness}

De Vries et al. (2012), Kujur and Singh (2017), Fortin and Dholakia (2005), and Tafesse (2015) defined the vividness of content in terms of its representational environmental richness and ability to represent reality and activate the senses. These authors also posited that vividness had a positive impact on engagement. The present study found that overall vivid content, which consisted of vivid-images and vivid-videos, provided better OCE rates for bounce rate which decreased by $28.96 \%$, average session duration which increased by $36.67 \%$, and average pages per session which increased by $25.81 \%$. A more detailed analysis found that when vivid content increased OCE is was primarily as a result of the vivid-video content having a higher positive influence on the OCE metric. For example, vivid-video content had a positive impact on bounce rate when compared to non-vivid video content with a decrease of $34.67 \%$, average session duration there was $75.86 \%$ increase, and pages per session there was a $45.45 \%$ increase. While vivid-text content only had a positive impact on bounce rate when compared to non-vivid text content with a decrease of $15.91 \%$, while pages per session had a $10.14 \%$ increase. Interesting to note was the fact that for OCE metrics average time on page there was an increase of $62.33 \%$ when non-vivid content was posted and for social engagement rate there was an increase of $28.17 \%$ indicating that for these metrics there were other antecedents other than whether the content was vivid that impacted positively influenced OCE.

More significantly, the present study also found support for the claim by Idler (2013) and Naylor (2018) that the human face plays a key role in driving engagement. 
When content showed a person or human face, the overall social engagement rate increased by $12 \%$. Compared to content that did not show a person or human face, which had an $11 \%$ increase in the social engagement rate on Facebook, $6 \%$ on ABC Investments' own platform and $1 \%$ on Instagram.

Resulting short-term strategy: content should be vivid and show person or human face in the thumbnail for the post.

\section{Content category}

This study also supported the finding by De Vries et al. (2012) and Tafesse (2015) that content category positively influences OCE. Results showed that content focused on food had an $89.44 \%$ increase in page views and $23.53 \%$ improvement in average session duration, more than content focused on events. Informative-focused content performed better than content focused on events, with a $42.95 \%$ increase in pages per session, a $22.73 \%$ improvement in bounce rate, and a $31.84 \%$ increase in social engagement rate. Users also spent, on average, $11.32 \%$ more time on pages with informative content than on content focused on food. Additionally, content focused on information and events ranked either first or second on half of the six OCE metrics.

Resulting short-term strategy: these results suggest that informational posts should form the bulk of content, while content focused on food and events should also be used to a lesser extent.

\section{Post frequency}

Tafesse (2015) indicated a positive relationship between the frequency of posting and OCE. The present study, however, found that frequency of posting only had a

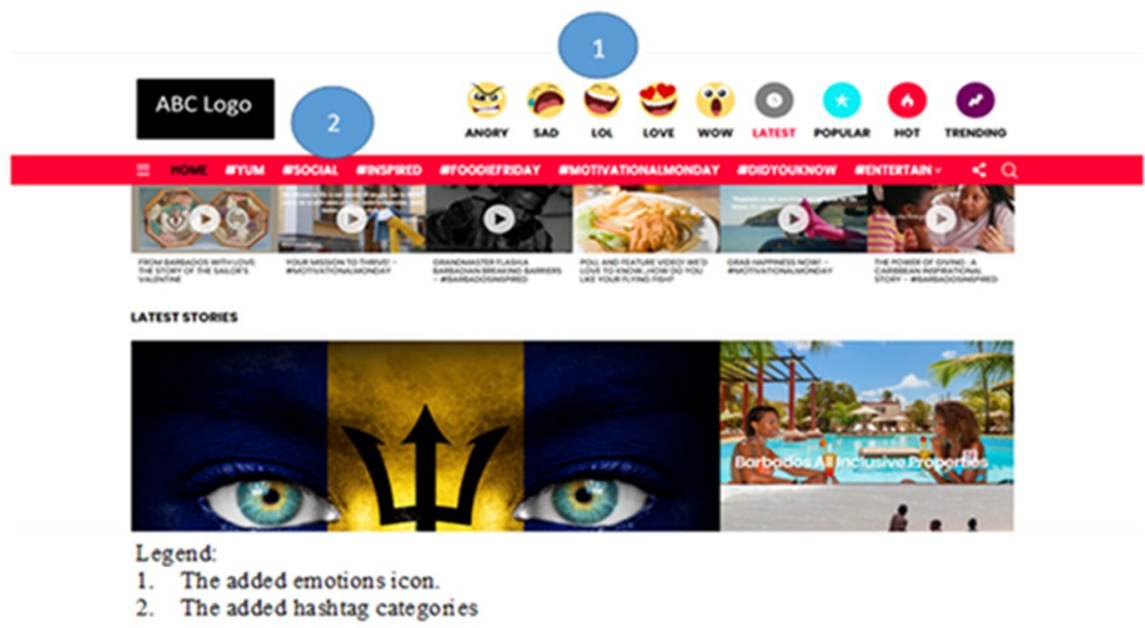

Fig. 5 Screenshot of $\mathrm{ABC}$ investments website showing user experience changes 
positive influence on the average time spent on a page, which showed an increase of $41.67 \%$ when post frequency increased. Another important finding was that higher post frequency had a negative impact on pages per session (a 7.95\% decrease), average session duration (26.92\% decrease), and bounce rate (23.25\% decrease). Results also showed higher OCE rates for certain age groups when posting frequency increased. However, time constraints did not permit a deeper analysis of the relationship between demographics and post frequency, so none of the age groups were eliminated during analysis targeting, except for users less than 18 years old. People under 18 were eliminated for ethical reasons; 18 is the age of majority in Barbados (the registered country of ABC Investments) and users cannot enter contracts before this age without permission from a parent or guardian (Forde 1991).

Resulting short-term strategy: these findings suggest that content should be posted several times a week (at least every other day) to take advantage of peak days and times for user engagement.

\section{Media elements}

Rauschnabel et al. (2012) posited that media elements were a viable antecedent for customer engagement, but their research only provided a general theory of media elements and did not provide any details regarding the quantity or type of media elements that would impact OCE. This study, in contrast, examined the impact of the quantity of media elements on OCE. Results showed that the number of media elements had a positive impact on OCE metrics. Specifically, there was a positive relationship between the number of media elements and pages per session, bounce rate, average session duration and average time on page. Further analysis also showed the highest engagement was attained when there were between 5 and 14 media elements in a single post. Results also showed diminishing returns in OCE when there were between 12 and 14 media elements.

Resulting short-term strategy: these findings suggest that posts or content should have between 6 and 11 media elements, avoiding the extreme lower (5) and higher (12) ends of the scale.

\section{Tailored experience}

Constantinides (2002), Pophal (2015), and Srinivasan et al. (2002) suggested that users are more likely to engage when a content marketing platform is tailored to their needs and usage patterns. For example, when the ABC platform was modified to provide users with a tailored experience, there was an improvement of $72.73 \%$ in the average time on page and a $30 \%$ increase in average session duration. Figure 5 illustrates these modifications, which involved the addition of emotion icons (number 1 in the Fig. 5) and hashtag categories (number 2 in Fig. 5) at the top of the menu to provide users with access to content in which they had previously shown some interest.- However, results also showed that tailoring the user experience had a negative impact on the number of pages viewed per session, which fell by $15.05 \%$, and on the bounce rate, which fell by $15.35 \%$. 
Resulting short-term strategy: these findings suggest that engagement can be improved by designing a content platform to allow users to easily find content that interests them via a "you may also like" link, branded menu categories (e.g., Foodie Fridays or Social), or reaction categories. They also suggest that allowing the automatic loading of the "you may also like" section keeps users engaged.

\section{Distribution channel}

Several authors have used Facebook as the basis for research on content marketing or OCE, including Bonsón and Ratkai (2013), Conroy et al. (2012) and Cvijikj and Michahelles (2013), but none of these authors considered social media platforms as distribution channels or discussed the impact that a specific platform may have on engagement. This study treated Facebook and Instagram as distribution channels for $\mathrm{ABC}$ Investments and sought to determine whether the distribution channel influenced engagement, specifically focusing on the social engagement rate. It was found that paid content tended to perform equally well on Instagram and Facebook, with social engagement rates of $26 \%$ and $27 \%$, respectively. On the other hand, when sponsored posts had links redirecting users to the ABC Investments platform, there was a social engagement rate of $13 \%$. However, the engagement rate for unpaid content was higher on Instagram (33\%), while it was lower on Facebook (11\%) and on ABC's platform (9\%). These results suggest that unpaid content achieves greater engagement on Instagram than on Facebook.

Resulting short-term strategy: these findings suggest that both Facebook and Instagram should be used for paid content, but that Instagram is a better channel for distributing unpaid content.

\section{SEO}

Although Van Doorn et al. (2010) discussed the influence of external factors on customer engagement, they did not include SEO among their engagement antecedents. In practice, harnessing SEO to increase engagement is essential for content marketing companies (Evans 2007). This study confirmed that there is a positive relationship between SEO and OCE metrics, with improvements in average time on page (up 31.58\%), bounce rate (down 12.25\%), pages per session (up 39.66\%), and average session duration (up 123.08).

Resulting short-term strategy: these findings suggest that content should be focused on trending or otherwise popular topics and that content or posts must be search engine optimised.

\section{Discovery percentage}

Discovery percentage was not included as an antecedent or strategy element in any of the reviewed research and was thus not among the initial research themes for this study. However, it emerged from one of the MMAR sessions as a possible antecedent during the qualitative interviews and replaced hashtag as an independent variable. Discovery percentage is one of the insight tools provided by Instagram to its 


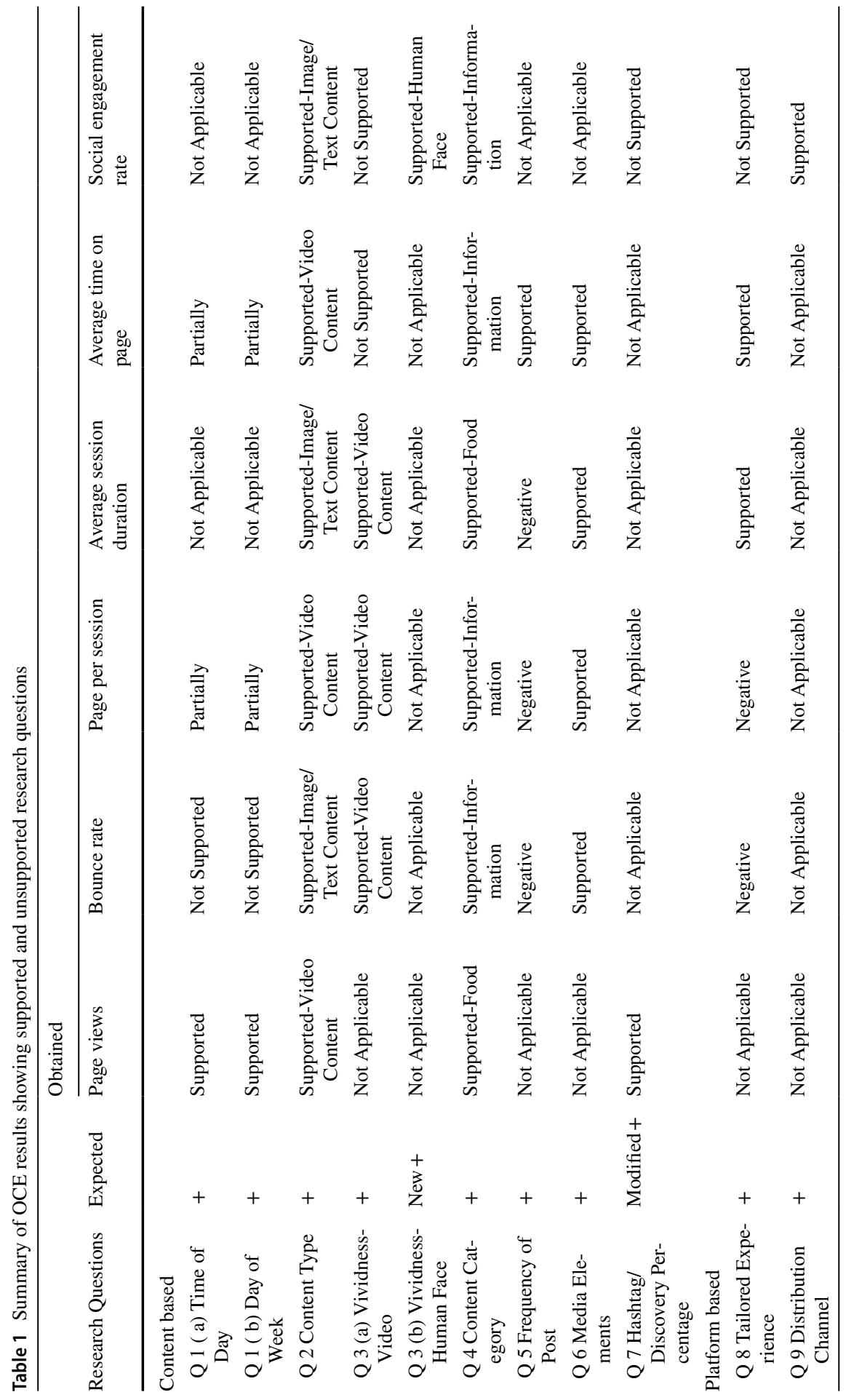




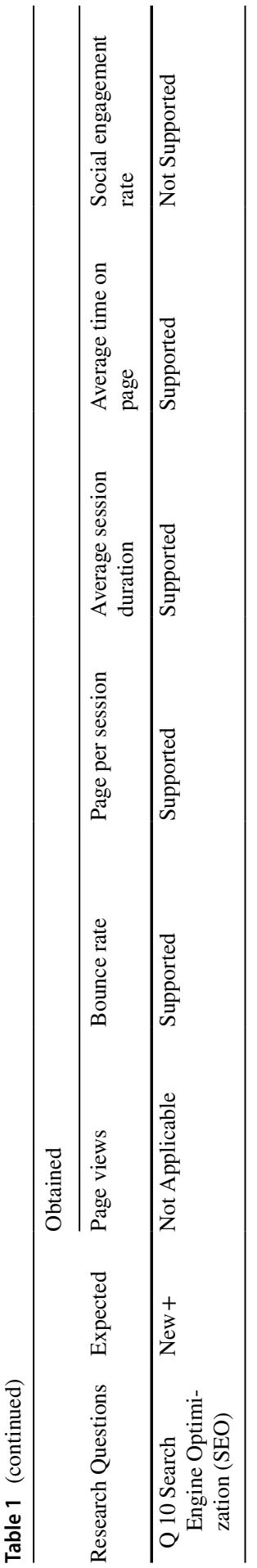

SN Business \& Economics 
business customers and is only visible from a mobile device. Instagram defines discovery percentage as the percentage of user accounts which are reached as a result of a post, but which are not following an account. The discovery percentage considers accounts that find a post via the home page, profile, hashtags or other sources. This antecedent proved to have a positive influence on page views, which has proven in the study to be one of the more difficult OCE metrics to improve. As the independent variable, the discovery percentage had an $R^{2}$ of 0.63333 , which meant that it explained $63.33 \%$ of the variance in page views (dependent variable). In contrast, the discovery percentage had an $R^{2}$ of 0.0049 for the social engagement rate (the dependent variable), therefore, explaining only $0.49 \%$ of the variance in this metric. Moreover, when more hashtags were used to ensure a discovery percentage of more than $90 \%$, page views increased by $1093 \%$. It should be noted as well that this organic method increased page views by at least twice as much as when content was sponsored or advertised.

Resulting short-term strategy: these findings highlight the value of identifying trending hashtags and creating relevant content to tag with them. The discovery percentage should be monitored to ensure that it is more than $90 \%$, thereby guaranteeing greater visibility.

A summary of the OCE results is presented in Table 1, which also shows the supported and unsupported research questions.

\section{Long-term strategies}

As part of the MMAR cycle, the research also highlighted the need for ABC Investments to develop a more sustainable, long-term strategy that takes into consideration the resource capabilities of the organization. This would involve a paradigm shift for $\mathrm{ABC}$ with the long-term strategy involving $95 \%$ of the content being created by ABC's users and the other 5\% being created by ABC's in-house content creators. However, the revised strategy would allow a new content marketing company similar to $\mathrm{ABC}$, or new content marketers to focus their limited resources on creating higher quality, longer, more innovative content since the pressure to post frequently would be removed. Users could now create their own content either via the company's platform, or via the creation of company or marketer's managed groups, community forums or sub-reddits within well established, larger social media platforms. Thereby using these existing social media platforms as distribution channels for the company's content, where the users are providing the relevant antecedent characteristics to organically drive OCE for the company or marketer's brand, such as posts that are frequent, content that is posted during the times and days that users are available, posts that focus on content categories that users are interested in, and posts that focus on trending topics.

Not Applicable indicate when a metric was not tested. 


\section{Summary, limitations and future work}

\section{Summary}

This research is among the first to analyse OCE data on three platforms, namely Facebook, Instagram and a start-up, ABC Investments. This research also acknowledges and analyses the impact that the need to distribute content on more established platforms may have on the engagement strategies of new content marketing companies, such as ABC Investments. This research, therefore, benefits academics, practitioners and new companies in ways that other research on content marketing and OCE has not.

The study focused on content-based and platform-based antecedents and their impact on specific OCE metrics. The overarching finding was that it is difficult, as a start-up to determine the relationship between the antecedents and metrics of OCE in the context of content marketing; and that the relationship is more complex than have been previously posited in the many studies on OCE and content marketing. Moreover, where researchers have identified relationships between antecedents and metrics, they have done so in the context of pristine, controlled environments. Unfortunately, however, for marketing practitioners, such environments tend to generate clear and direct associations (one-to-one or one to all) between the antecedents and metrics of OCE which is an unrealistic expectation within a real-world environment. This research, by contrast, was conducted in a real-world setting, with all the nuances that arise in such complex environments. The results showed that, in most instances, there is no one-to-one relationship between antecedents and metrics, but that an antecedent can increase the performance of specific metrics while at the same time decreasing the performance or having no impact on other metrics. For example, this study showed that the antecedents time of day and day of the week positively increased performance of page views, however, neither of these antecedents had an impact (i.e. neither increase nor decrease performance) on bounce rate. On the other hand, the antecedent tailored experience positively increased performance of average session duration and average time on page, while it provided a decreased performance of bounce rate and pages per session. As such, these findings can, therefore, facilitate a new content marketer's understanding of the nuances of OCE and how to make changes in their online strategy to achieve increased customer engagement.

This study also contributes significantly to the research into OCE and content marketing by extending the work of Tafesse (2015), Fortin and Dholakia (2005), and De Vries et al. (2012) to show that the definition of vividness should include the variable of a human face. This research also extends the work by Tse and Soufani (2003), Kee and Yazdanifard (2015), Constantinides (2002), Mahajan and Venkatesh (2000), Kalyanam and McIntyre (2002) and Evans (2007) by demonstrating the impact which antecedents, such as distribution channels and SEO, have on real-world OCE metrics. A third important outcome of this research is that it adds a new antecedent, discovery percentage, to the list of important OCE variables developed by Van Doorn et al. (2010), Kujur and Singh (2017), Moro et al. (2016) and 
Cvijikj and Michelles (2013). This variable proved to have the greatest impact on page views, which is usually one of the hardest metrics for marketing practitioners to improve, as indeed it was in this study.

\section{Limitations and future work}

One of the main limitations of the research came from its methodology, namely MMAR. Action Research is not intended to provide generalised results therefore, although the research provides practitioners and academics with insight into the drivers of OCE, its results cannot be generalised (Kemmis et al. 2014). As such, there is scope for future research work into OCE that uses a more generalised method.

Another limitation is that this paper documents research performed on a new content marketing company, so the dataset was not as large as those used within the studies done by Cvijikj and Michahelles (2013), Evans (2007), De Vries et al. (2012) nor Tafesse (2015). Further research on a more established company with a larger dataset is, therefore, required to determine if the results of this study are broadly applicable.

Finally, because the research dataset consisted of summary data, it was impossible to fully explore the impact of demographics on OCE. However, although much of the literature on OCE and content marketing focuses on customer-based and platform-based antecedents as the main drivers of engagement, future research on OCE should include user differentiators such as age, gender, and location.

Despite these limitations, this work is valuable in its own right to both academics and practitioners and provides opportunities for future research.

Author contributions The principal author, CDW, contributed to the study conception and design. Material preparation, data collection and analysis were performed by CDW. The first draft of the manuscription was written by CDW. CDW approved the final manuscript.

Funding No funding, grants or other support was received for this study.

Availability of data and material The data that support the findings of this study are available from the author upon reasonable request and with permission of the Principal Director of ABC Investments. The data and material will be available for at least 10 years after the completion of the original research as was part of the University of Liverpool's DBA research ethics requirements.

Code availability No specific software application or custom code was used in this study.

\section{Declarations}

Conflict of interest The author, Cynthia D. Wiggins is the Principal Director of ABC Investments (pseudonym) which the study was based on and was also the student investigator for the study but received no compensation in respect to the study.

Ethical approval Ethics approval was awarded on 23 February 20218, by the University of Liverpool's DBA Ethics Committee. 
Consent to participate All participants were provided with a University of Liverpool Participant Information Sheet version 1/ July 19, 2017 to provide consent and which formed part of the ethics requirements of the University of Liverpool on which the ethics approval awarded on 23 February 20218 was based.

Consent to publication Consent was given by the Principal Director of ABC Investments (Cynthia Wiggins) on January 15, 2018 to access and download data from the ABC Investments platform and formed part of the ethics requirements of the University of Liverpool on which the ethics approval awarded on 23 February 20218 was based.

Open Access This article is licensed under a Creative Commons Attribution 4.0 International License, which permits use, sharing, adaptation, distribution and reproduction in any medium or format, as long as you give appropriate credit to the original author(s) and the source, provide a link to the Creative Commons licence, and indicate if changes were made. The images or other third party material in this article are included in the article's Creative Commons licence, unless indicated otherwise in a credit line to the material. If material is not included in the article's Creative Commons licence and your intended use is not permitted by statutory regulation or exceeds the permitted use, you will need to obtain permission directly from the copyright holder. To view a copy of this licence, visit http://creativecommons.org/licen ses/by/4.0/.

\section{References}

Abdul-Ghani E, Hyde KF, Marshall R (2011) Emic and etic interpretations of engagement with a consumer-to-consumer online auction site. J Bus Res 64(10):1060-1066. https://doi.org/10.1016/j. jbusres.2010.10.009

Ailawadi KL, Lehmann DR, Neslin SA (2003) Revenue premium as an outcome measure of brand equity. J Mark 67(4):1-17. https://doi.org/10.1509/jmkg.67.4.1.18688

Ashley C, Tuten T (2015) Creative strategies in social media marketing: an exploratory study of branded social content and consumer engagement. Psychol Mark 32(1):15-27. https://doi.org/10. 1002/mar.20761

Baltes LP (2015) Content marketing-the fundamental tool of digital marketing. Bull Transilv Univ Brasov Econ Sci Ser V 8(2):111

Berman SJ (2012) Digital transformation: opportunities to create new business models. Strategy Leadersh 40(2):16-24. https://doi.org/10.1108/10878571211209314

Bonsón E, Ratkai M (2013) A set of metrics to assess stakeholder engagement and social legitimacy on a corporate Facebook page. Online Inf Rev 37(5):787-803

Cheong Y, De Gregorio F, KiM K (2010) The power of reach and frequency in the age of digital advertising: offine and online media demand different metrics. J Advert Res 50(4):403-415. https://doi.org/10.2501/S0021849910091555

Chua AY, Banerjee S (2013) Customer knowledge management via social media: the case of Starbucks. J Knowl Manag 17(2):237-249. https://doi.org/10.1108/13673271311315196

Conroy M, Feezell JT, Guerrero M (2012) Facebook and political engagement: a study of online political group membership and offline political engagement. Comput Hum Behav 28(5):1535-1546. https://doi.org/10.1016/j.chb.2012.03.012

Constantinides E (2002) The 4S web-marketing mix model. Electron Commer Res Appl 1(1):57-76. https://doi.org/10.1016/S1567-4223(02)00006-6

Constantinides E, Romero CL,Boria MAG (2008) Social media: a new frontier for retailers?. In European Retail Research: 1-28. Gabler Verlag, Wiesbaden. https://doi.org/10.1007/ 978-3-8349-8099-1_1

Creswell J (2003) Research design: qualitative, quantitative, and mixed methods approaches, 2nd edn. GBR: SAGE Publications Ltd, London

Cvijikj IP, Michahelles F (2013) Online engagement factors on Facebook brand pages. Soc Netw Anal Min 3(4):843-861

De Vries L, Gensler S, Leeflang PS (2012) Popularity of brand posts on brand fan pages: an investigation of the effects of social media marketing. J Interact Mark 26(2):83-91. https://doi.org/10.1016/j. intmar.2012.01.003 
Easterby-Smith M, Jackson P, Thorpe R (2012) Management research, 4th edn. GBR: SAGE Publications Ltd, London, London

Elsayed AM (2017) Web content strategy in higher education institutions: the case of King Abdulaziz University. Inf Dev 33(5):479-494

Evans MP (2007) Analysing Google rankings through search engine optimization data. Internet Res 17(1):21-37. https://doi.org/10.1108/10662240710730470

Farris PW, Bendle NT, Pfeifer PE, Reibstein DJ (2006) Marketing metrics: 50+ metrics every executive should master. Wharton School Publishing, New Jersey

Forde NM (1991) Barbados: family law and social change. J Fam L 30:263

Fortin DR, Dholakia RR (2005) Interactivity and vividness effects on social presence and involvement with a web-based advertisement. J Bus Res 58(3):387-396. https://doi.org/10.1016/S0148-2963(03) 00106-1

Harmeling CM, Moffett JW, Arnold MJ, Carlson BD (2017) Toward a theory of customer engagement marketing. J Acad Mark Sci 45(3):312-335. https://doi.org/10.1007/s11747-016-0509-2

Highfield T, Leaver T (2015) A methodology for mapping Instagram hashtags. First Monday 20(1):1-11. https://doi.org/10.5210/fm.v20i1.5563

Huffman S (2012) Growing reddit- web development. Available via UDACITY. https://www.youtube. com/watch?time_continue $=72 \& v=$ zmeDzx 4 SUME Accessed 15 Feb 2019

Idler S (2013) The effect of human faces in web design - the latest voice of customer and CX trends I Usabilla Blog. The Latest Voice of Customer and CX trends I Available via USABILLA BLOG https://usabilla.com/blog/effect-human-faces-web-design/ Accessed 15 Feb 2019

Smart Insights. (2021). Global social media research summary [updated 2021]. Available via SMART INSIGHT https://www.smartinsights.com/social-media-marketing/social-media-strategy/newglobal-social-media-research/ Accessed 7 Apr 2021

Islam JU, Rahman Z (2017) The impact of online brand community characteristics on customer engagement: an application of Stimulus-Organism-Response paradigm. Telematics Inform 34(4):96-109. https://doi.org/10.1016/j.tele.2017.01.004

Ivankova N, Wingo N (2018) Applying mixed methods in action research: Methodological potentials and advantages. Am Behav Sci 62(7):978-997. https://doi.org/10.1177/0002764218772673

Kalyanam K, McIntyre S (2002) The e-marketing mix: a contribution of the e-tailing wars. J Acad Mark Sci 30(4):487-499. https://doi.org/10.1177/009207002236924

Kee AWA, Yazdanifard R (2015) The review of content marketing as a new trend in marketing practices. Economics 2(9):1055-1064

Kemmis S, McTaggart R, Nixon R (2014) The action research planner: doing critical participatory action research. Springer Science \& Business Media, Singapore

Kim J, Lennon SJ (2013) Effects of reputation and website quality on online consumers' emotion, perceived risk and purchase intention: based on the stimulus-organism-response model. J Res Interact Mark 7(1):33-56. https://doi.org/10.1108/17505931311316734

Koch OF, Benlian A (2015) Promotional tactics for online viral marketing campaigns: how scarcity and personalization affect seed stage referrals. J Interact Mark 32:37-52. https://doi.org/10.1016/j.intmar.2015.09.005

Kujur F, Singh S (2017) Engaging customers through online participation in social networking sites. Asia Pac Manag Rev 22(1):16-24. https://doi.org/10.1016/j.apmrv.2016.10.006

Landsverk KH (2014) The instagram handbook: 2014 edition, 1st edn. PrimeHead Limited, London

Mahajan V, Venkatesh R (2000) Marketing modeling for e-business. Int J Res Mark 17(2-3):215-225. https://doi.org/10.1016/S0167-8116(00)00022-7

Mehrabian A, Russell JA (1974) An approach to environmental psychology. Mass MIT Press, Cambridge

Moro S, Rita P, Vala B (2016) Predicting social media performance metrics and evaluation of the impact on brand building: a data mining approach. J Bus Res 69(9):3341-3351. https://doi.org/10.1016/j. jbusres.2016.02.010

Naylor TJ (2018) Reasons why putting a human face in your marketing campaign is an essential strategy. Available via BUSINESS 2 COMMUNITY. https://www.business2community.com/marketing/ reasons-why-putting-a-human-face-in-your-marketing-campaign-is-an-essential-strategy-02104065 Accessed 6 Jan 2019

Pansari A, Kumar V (2017) Customer engagement: the construct, antecedents, and consequences. J Acad Mark Sci 45(3):294-311. https://doi.org/10.1007/s11747-016-0485-6

Peng C, Kim YG (2014) Application of the stimuli-organism-response (SOR) framework to online shopping behavior. J Internet Commer 13(3-4):59-176 
Perrin A (2015) Social media usage 2005-2015. Available via Pew Research Center from http://www. pewinternet.org/2015/10/08/2015/Social-Networking-Usage-2005-2015/ Accessed 14 Apr 2021

Peters K, Chen Y, Kaplan AM, Ognibeni B, Pauwels K (2013) Social media metrics-a framework and guidelines for managing social media. J Interact Mark 27(4):281-298. https://doi.org/10.1016/j.intmar.2013.09.007

Pilon A (2017) 80 percent of small businesses use Facebook for marketing, new survey says—small business trends. Available via SMALL BUSINESS TRENDS https://smallbiztrends.com/2017/09/topsocial-media-sites-for-marketing-small-business.html Accessed 22 Jan 2019

Pophal L (2015) Small business and content marketing. Econtent 38(3):6-8

Rauschnabel PA, Praxmarer S, Ivens BS (2012) Social media marketing: how design features influence interactions with brand postings on Facebook. In: Langner T, Okazaki S,Eisend M (eds) Advances in Advertising Research, vol 3. Gabler Verlag, Wiesbaden. p 153-161. https://doi.org/10.1007/9783-8349-4291-3_12

Sandelowski M (2000) Combining qualitative and quantitative sampling, data collection, and analysis techniques in mixed-method studies. Res Nurs Health 23(3):246-255. https://doi.org/10.1002/1098240X(200006)23:3\%3C246::AID-NUR9\%3E3.0.CO;2-H

Srinivasan SS, Anderson R, Ponnavolu K (2002) Customer loyalty in e-commerce: an exploration of its antecedents and consequences. J Retail 78(1):41-50. https://doi.org/10.1016/S0022-4359(01) 00065-3

Sun T, Youn S, Wu G, Kuntaraporn M (2006) Online word-of-mouth (or mouse): an exploration of its antecedents and consequences. J Comput-Mediat Commun 11(4):1104-1127. https://doi.org/10. 1111/j.1083-6101.2006.00310.x

Tafesse W (2015) Content strategies and audience response on Facebook brand pages. Mark Intell Plan 33(6):927-943. https://doi.org/10.1108/MIP-07-2014-0135

Thakur R (2016) Understanding customer engagement and loyalty: a case of mobile devices for shopping. J Retail Consum Serv 32:151-163. https://doi.org/10.1016/j.jretconser.2016.06.004

Tse T, Soufani K (2003) Business strategies for small firms in the new economy. J Small Bus Enterp Dev 10(3):306-320. https://doi.org/10.1108/14626000310489781

Van Doorn J, Lemon KN, Mittal V, Nass S, Pick D, Pirner P, Verhoef PC (2010) Customer engagement behavior: theoretical foundations and research directions. J Serv Res 13(3):253-266. https://doi.org/ $10.1177 / 1094670510375599$ 